\title{
Decent Work as a Necessary Condition for Sustainable Well-Being. A Tale of Pi(i)gs and Farmers
}

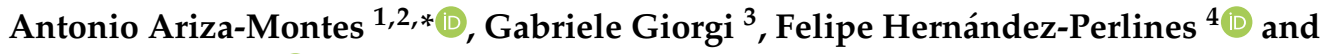 \\ Javier Fiz-Perez ${ }^{3}$ (D) \\ 1 Department of Management, Universidad Loyola Andalucía, 14004 Córdoba, Spain \\ 2 Facultad de Administración y Negocios, Universidad Autónoma de Chile, 425 Santiago, Chile \\ 3 Department of Human Sciences, Università Europea di Roma, 00169 Rome, Italy; \\ prof.gabriele.giorgi@gmail.com (G.G.); javier.fizperez@unier.it (J.F.-P.) \\ 4 Department of Business Administration, University of Castilla-La Mancha, 45071 Toledo, Spain; \\ Felipe.HPerlines@uclm.es \\ * Correspondence: ariza@uloyola.es
}

Received: 11 December 2018; Accepted: 14 February 2019; Published: 18 February 2019

\begin{abstract}
This article analyzes with a holistic and systematic approach the state of working conditions in the European labor market after the crisis, as well as their effects on worker well-being. For this, a distinction will be made between the southern countries most affected, namely Portugal, Italy, Ireland, Greece, and Spain (Piigs), and the northern countries that are, a priori, less damaged by the crisis (Farmers). The samples integrate 7867 workers from the five Piigs countries (36.2\%) and 13,894 from the 10 Farmers countries $(63.8 \%)$. The results have broadly confirmed the research purposes and they established that ensuring well-being is the key to sustainability, growth, and success for workers, groups, and organizations.
\end{abstract}

Keywords: sustainability; job quality; well-being; work intensity; social environment

\section{Introduction}

Human work has a prominent social dimension, since it makes up a source of economic resources for workers, but it also represents a way for integration into society and, ultimately, is an instrument of personal fulfillment. From this point of view, as indicated by [1], people do not work just to make a living. For this reason, the quality of work life is a key element in quality-of-life.

Among the 17 Sustainable Development Goals proposed by [2] to achieve a better and more sustainable future for all, there are two that are directly related to the labor world: the commitment with decent work (Goal 8) and the promotion of health and well-being (Goal 3). The sustainable development of any society demands thinking seriously about these matters. More precisely, the psychology of sustainability and sustainable development [3] sees sustainability not only in terms of the ecological and socioeconomic environment but also in terms of improving the quality of life of every person. From this perspective, analyzing the labor market and job quality is essential because work plays a key role in the health and well-being of workers. However, the maelstrom of changes that are taking place in the current labor market (flexible employment, nonstandard work contracts, greater insecurity, lack of protection, etc.) means that both the psychological and physical well-being of workers is under threat [4].

These threats are of particular concern in the European context, which has been hit hard by the economic and financial crisis that began in 2008 and has resulted in a clear disrepair of the welfare state, especially as a result of austerity measures applied since 2010 in some countries, materialized as hard adjustments to social spending and the labor market. Nevertheless, this policy has not been applied 
uniformly throughout the European Union. In contrast, the convergence process of recent decades has been transformed into deep divergences that will likely soon be irreparable. These regressive trends in the labor market have created fractures and impoverishment, particularly in peripheral European countries, to the point of generalizing a derogatory acronym to designate these nations: PIGS (so-called because it originally referred to the economies of Portugal, Italy, Greece and Spain, although later Ireland was added, thus forming the PIIGS variant). Austerity policies have generated a fragmented Europe between the north and the south, with the labor market being one of the elements in which the economic and social gap is surely deeper.

The crisis has not gone free. In contrast, after almost a decade of adjustments, the European labor market is poorer and more precarious (especially in the "Piigs" countries), which has probably translated into less sustainable development in the form of impoverishment of levels of well-being. For this reason, it is appropriate to analyze perceived job quality and worker well-being in the European context after the crisis, distinguishing between the five "most filthy" countries (Piigs) and the other ten that jointly make up the EU-15 (henceforth referred to as "Farmers").

Although the need to deepen studies that relate job quality and employee well-being seems obvious, the fact is that the debate on this issue is still ongoing, largely due to the inability of the literature to agree on a rigorous concept of what is meant by job quality. This research adopts an objective perspective of job quality, which means that the attention is focused on the main characteristics of work that can be observed and are related to the satisfaction of worker needs. These features have proven their effect on the health and well-being of workers (e.g., [5-7]). In this research, we use psychological well-being measured through the Well-Being Index (WHO-5) as an outcome variable. Since its first publication in 1998, this index has been translated into numerous languages and used in many studies worldwide. This concept developed by the World Health Organization assesses constructs of positive mood, vitality and general interests and considers well-being as a state of happiness or general satisfaction with life, as opposed to the antagonistic concept of ill-being.

More precisely, this is the main objective of this paper, to analyze with a holistic and systematic approach the state of working conditions in the European labor market after the crisis, as well as their effects on worker well-being. For this, a distinction will be made between the southern countries most affected (Piigs) and the northern countries that are, a priori, less damaged by the crisis (Farmers). With this approach, we cover an important research gap, since previous studies usually dealt with this question in a partial or fragmented way, identifying some isolated working conditions that are undoubtedly of interest but that fail to give a complete overview of the job quality problem and its relation to sustainable development. Moreover, past research has neglected the value that positive psychology has for the encouragement of positive work environments, which leads to greater employee health, well-being, and performance [8].

\section{Job Quality and Well-Being}

Job quality is a multifaceted concept [9] that is elusive [1] and has evolved over time [10]. These authors note that in the 1970s, more attention was paid to the intrinsic features of work, such as physical and psychological stress, but the concept was then broadened to cover other traits, such as skills development, flexibility and security of employment, and, more recently, began to include issues such as reconciliation of employment and family tasks.

The initial sociological and psychological studies of the early literature of perceived job quality linked the concept of job quality to job satisfaction and a worker's physical, mental and emotional health and well-being, which had strong effects on organizations' results [11]. However, in the most recent literature, two approaches have emerged [12]: a more subjective one, concerning certain peculiarities of workers (attitudes, motivation, satisfaction, commitment, involvement, loyalty, etc.) and a more objective one, related to the work environment (safety, physical and psychological conditions, social support, job stability, etc.). 
The evolution of the job quality concept has undoubtedly hindered the analysis and understanding of this complex phenomenon, but knowing what makes a good job (perceived job quality) is vital to knowing how well society is doing [13]. Therefore, what should be understood as being a good job? From a general point of view, [12] believe that high quality jobs are those that improve the working conditions of employees, facilitate the development of their skills and competences, reduce unemployment, increase company productivity, contribute to economic competitiveness and promote individual and social well-being in an increasingly globalized environment. From this perspective, [14] defines job quality as the set of work features that foster the well-being of the worker; therefore, a good job-a decent job-is one that allows workers to reach a level of well-being suitable to their vital expectations, as well as a range of personal objectives that vary from one individual to another. Given the multidimensional nature of perceived job quality, the elements that generate such well-being are those linked to employment and job characteristics (hours, wage, skills required, etc.), the general working environment and the labor market (working conditions, training, equal opportunities, etc.) and workers' subjective perception or appraisal of their jobs (job satisfaction, career expectations, etc.) [15].

The conceptual muddle has moved to the measurement arena so that there are currently two approaches that cannot reach an agreement: the European Union agenda, developed in the beginning of 2000 within the framework of the European Employment Strategy for creating "more and better jobs", and the one concerning the "decent work" concept, promoted by the International Labor Organization (ILO) since 1999. Although Europe currently leads the debate on job quality, the truth is that the origin of this concern should be placed in the 1980s, when in the United States and other predominantly English-speaking countries began to discuss the decency of work due to the emergence of a new, more unstable, discontinuous and lower-paying employment model [16].

Although both agendas have been developed in parallel, proponents of the two agendas have not been able to agree on a common approach. For the ILO, the concept of decent work is founded on the principles of freedom, equality, security, and human dignity [17], including four main components: employment, social security, labor rights and social dialogue. From this point of view, decent work not only makes an appreciable contribution to sustainable development but is also a leading objective in itself, as it constitutes a key dimension of life quality [18]. Therefore, in this view, the concept of decent work is broader and more focused on the "quality of employment", reflecting the general employment situation of a geographical area.

For its part, job quality puts the focus on the worker and individual labor conditions. In this sense, job quality constitutes a component of decent work. According to [9], this double view leads to a dilemma of principles, since the first approach takes into consideration individual circumstances, including aspects of the work environment, such as the unemployment rate. However, the second proposal aims to obtain a measure of job quality independent of personal circumstances and labor market conditions; that is, it tries to identify the objective features of the work that meet the worker's needs. Following the recommendations of [1], the present research will adopt this last approach.

There is no doubt is that Europe possess more and better data to survey job quality than other parts of the world. As stated by [19], only in Europe there is solid and reliable information - that is, comparable indicators from harmonized surveys. This is only the case because in early 2000, the EU launched the European Employment Strategy aimed at creating more (quantity) and better (quality) jobs in Europe. Based on the assumption that any job quality index should be strictly restricted to evaluating those labor aspects that exert a clear and direct effect on workers' well-being, the approach fostered by the European Foundation for Living and Working Conditions for the design of the European Working Conditions Survey-EWCS asks workers about the intrinsic characteristics of their jobs, such as wages, working time conditions or job security, among others.

The conceptual framework of job quality proposed in Europe is developed from this objective perspective. This covers four key dimensions: career and employment security, health and well-being, reconciliation of working and nonworking life and skills development [9]. After subsequent 
improvements, the sixth edition of the European Working Conditions Survey (EWCS-2015) proposed the European Job Quality Index (JQI), which establishes the seven essential dimensions that influence (positively or negatively) the health and well-being of workers.

Physical environment. This dimension takes into account the physical risks that employees encounter at their workplaces. The elimination or minimization of physical risks is a core element of occupational health and safety policy in the member states of the EU, framed within the long-term strategy of European social policy. Several studies have analyzed the relationship of the physical work environment to the health and well-being of workers, giving rise to a remarkable body of knowledge about occupational well-being (e.g., [5,20-22]).

Work intensity. This dimension refers to the intensity of labor demands associated with the performance of a certain job. Numerous epidemiological studies have shown that a work environment subjected to high demands (especially when this situation is combined with limited decision latitude and limited social support) is negatively associated with a deterioration of well-being and an increased risk of suffering certain diseases (cardiovascular disease, musculoskeletal disease, depression, etc.). Many of these studies have been developed from the perspective of the job demand-control-support model of occupational stress [23,24].

Working time quality. Organization and length of working time is important to evaluate job quality because these factors play a significant role in the health and well-being of workers [20], as does the need to achieve a good balance between working time and personal time. Many researchers have shown the effects that certain characteristics of working hours (e.g., long working hours, shift work, unsocial hours, night work, etc.) exert on aspects of health such as depression, anxiety, fatigue, quality of sleep, gastrointestinal and musculoskeletal disorders, and, among others, coronary heart disease $[5-7,25]$.

Social environment. The quality of the social environment at work is a critical aspect for development and personal growth. This index measures the degree to which workers perceive either social support relationships or adverse social behaviors. On the one hand, the social support of managers and colleagues and their relationship to the satisfaction of needs and the generation of well-being is well documented in the literature (a meta-analytic review about this topic can be consulted in the work of [26]. There is also a vast bibliography about the negative effects of adverse social behaviors, such as workplace bullying (this subject can be explored in the systematic reviews carried out by [27-29].

Skills and discretion. This dimension refers to the skills necessary to perform a certain job, as well as the autonomy that the worker has to apply them. Therefore, this index assesses the worker's ability to understand and influence how he carries out his work. The level of discretion (also called decision latitude) is a core element of Karasek's job demand-control-support model [23]. Various researchers have shown that a low level of discretion is linked to greater risk health problems, such as musculoskeletal disorders, cardiovascular disease, and mental health [20].

Prospects. This indicator integrates two elements that contribute directly to satisfying workers' material and psychological needs related to their self-esteem and identities: job security and the prospect of career advancement. The academic literature recognizes the direct relationship of job insecurity and the health and well-being of the workers (this subject is discussed in the review by [30]. Another recent systematic review has highlighted the negative impacts of restructuring processes on the well-being of workers, both those leaving the company and those who remain in their jobs [31].

Earnings. Many of the job quality indicators presented above focus on the immaterial features of the work. Nevertheless, the nuclear role of earnings as a motivational factor is undeniable, since earnings define, to a considerable extent, the workers' personal and family lifestyles, as well as their social status. Many researchers have included the variable of income in well-being studies. (e.g., $[13,32,33])$.

As seen in the previous paragraphs, each of these seven dimensions contains a large number of individual indicators that allow a systematic and holistic analysis of job quality in a specific activity 
sector or geographical area, which is why this framework constitutes a simple and swift diagnostic tool [34] that will be very useful for the purpose of the present investigation.

\section{Research Purposes}

Based on the above, the present research questions whether there is a positive relationship between workers' well-being and each of the seven dimensions of perceived job quality when considered together, even after checking for basic demographic variables. To this end, an empirical study was designed with three basic research purposes.

(1) First, an exploratory analysis of the evolution of perceived job quality and well-being in the period of 2010-2015 will be carried out for the two groups investigated (Piigs and Farmers).

(2) Second, a comparative descriptive analysis will be undertaken to establish whether the present job quality in Piigs countries is, in fact, more precarious than in Farmers countries, as well as to establish the degree of workers' well-being.

(3) Finally, a statistical analysis will be performed that reveals the job quality dimensions that define the workers' well-being in each of the two groups investigated.

\section{Methodology}

\subsection{Sample}

This research uses self-reported features of jobs in the sixth European Working Conditions Survey (EWCS) to build seven separate indices of perceived job quality. [10] note that the most common approach to benchmark job quality in a multidimensional index has been to use the EWCS. This survey delves into the working conditions of European workers, offering a wide-ranging overview (autonomy and work organization, physical and psychological risks, occupational health, work-life balance, etc.) by occupation, sector and age group [20]. The EWCS is developed by the European Foundation for the Improvement of Living and Working Conditions (www.eurofound.europa.eu), an agency of the European Union which focuses on managing research, gathering information, and communicating its findings. It was set up in May 1975 by the European Council to help improve living and working conditions across Europe. Since its launch in 1990, the European Working Conditions Survey is conducted every five years, providing an overview of working conditions in Europe. The scope of the survey questionnaire includes employment status, working time duration and organization, work organization, learning and training, physical and psychosocial risk factors, health and safety, work-life balance, worker participation, earnings and financial security, as well as work and health. The sample is a multistage, stratified random sample of the working population in each country. The survey was questionnaire-based with interviews conducted face to face in people's homes, with an average duration of $45 \mathrm{~min}$, and in the national language(s) of the country. Full details of the survey methodology are available on https://www.eurofound.europa.eu/sites/default/files/ef_survey/ field_ef_documents/6th_ewcs_-_technical_report.pdf.

To assess whether the crisis has degenerated into poorer job quality in Europe (particularly in the Piigs countries when compared to the Farmers), 15 countries were selected that formed the EU-15 after the incorporation of Austria, Finland and Sweden in 1995. The subsequent territorial enlargements of 2004, 2007, and 2013 have not been considered. The latest member states (most of Eastern Europe, independent after the breakup of the former Soviet Union) are not in this research due to their recent incorporation into the European Union, which has prevented them from benefiting from the convergence policies. Thus, the 15 countries were segmented into two subsamples at different times, 2015 and 2010: 7867 workers (5548 in 2010) from the five Piigs countries (36.2\%) and 13,894 $(16,876$ in 2010$)$ from the 10 Farmers countries $(63.8 \%)$. The sample is a multistage, stratified, random sample of the working population in each country. The interviews were conducted face to face in people's homes, with an average duration of $45 \mathrm{~min}$, and in the national language(s) of the country.

The main descriptive traits of the two samples are shown in Table 1. 
Table 1. Samples description.

\begin{tabular}{cccccc}
\hline \multirow{2}{*}{ Sex (\%) } & & \multicolumn{2}{c}{2015} & \multicolumn{2}{c}{ 2010 } \\
\hline \multirow{2}{*}{ Age (years) } & Piigs & Farmers & Piigs & Farmers \\
\cline { 2 - 6 } & Memale & 51.2 & 50.1 & 51.3 & 49.9 \\
\cline { 2 - 6 } & Mean & 48.8 & 49.9 & 48.7 & 50.1 \\
\cline { 2 - 6 } & Stand. Deviation & 12.2 & 12.6 & 11.8 & 12.1 \\
\hline \multirow{2}{*}{ Education (\%) } & Primary level & 29.8 & 16.1 & 33.4 & 20.8 \\
\cline { 2 - 6 } & Secondary level & 41.4 & 46.4 & 41.9 & 42.4 \\
\cline { 2 - 6 } & University level & 28.9 & 37.5 & 24.7 & 36.8 \\
\hline \multirow{2}{*}{ Seniority (years) } & Mean & 11.7 & 10.8 & 10.7 & 10.2 \\
\cline { 2 - 6 } & Stand. Deviation & 11.1 & 10.3 & 10.3 & 9.8 \\
\hline
\end{tabular}

\subsection{Measures}

The World Health Organization's Well-Being Index (WHO-5 items) is the dependent variable of this research. This index is among the most widely used questionnaires assessing subjective psychological well-being [35], evaluating the following aspects: positive mood (two items evaluate good spirit and relaxation: (1) I have felt cheerful and in good spirits and (2) I have felt calm and relaxed), vitality (two items evaluate being active and waking up fresh and rested: (3) I have felt active and vigorous and (4) I woke up feeling fresh and rested) as well as general interest (one item evaluated being interested in things: (5) My daily life has been filled with things that interest me). Respondents answer on a Likert scale that ranges from 0 ("at no time") to 5 points ("most of the time"). The index score ranges from 0 to 100, so that a higher score means greater well-being, while a lower score implies that workers are at greater risk of suffering mental health problems. The construct validity of this scale can be checked in [36].

The independent variables are the different dimensions of the Job Quality Index (JQI). This index encapsulates a wide range of employment peculiarities that are summarized in the seven dimensions that evaluate the job quality. The results can be interpreted as a synthetic measure of perceived job quality as a whole, broken down by the seven dimensions of the index but also beyond that into single items making up each dimension (due to each of these dimensions containing many individual indicators) [34]. Each of the scales comprises a series of questions designed to obtain a score of the objective properties of the respondents' jobs: (1) Physical environment, composed of 13 items grouped in posture-related (ergonomic) risks (exposure to tiring positions, lifting people, carrying heavy loads and repetitive movements), ambient risks (exposure to vibration, noise, and high and low temperatures), and biological and chemical risks (exposure to inhaling smoke and toxic vapors and handling chemical products and infectious materials); (2) Work intensity, comprising 13 items related to quantitative demands (working fast and time pressure-having tight deadlines, not having enough time to do the job, and frequent disruptive interruptions), pace determinants and interdependency (colleagues, boss, customers, performance targets, etc.), and emotional demands (being in situations that are emotionally disturbing, hiding feelings at work, and handling angry clients, patients, pupils, etc.); (3) Working time quality, composed of four dimensions, such as duration (long working hours or days and scarce rest between two consecutive work days), atypical working time (night work, weekend work and shift work), working time arrangements (control over working time arrangements), and flexibility (the need to work in the free time to meet work demands and the possibility of taking a few hours off during the workday to attend personal matters); (4) Social environment, comprising two dimensions and 15 indicators, such as adverse social behavior (exposure to verbal abuse, unwanted sexual attention, physical violence, bullying, etc.), and social support (management quality and support from colleagues and managers); (5) Skills and discretion, composed of 14 items referring to the skill 
content of the job or cognitive dimension (e.g., solving unforeseen problems, carrying out complex tasks, learning new things and ability to apply one's own ideas at work), decision latitude (ability to choose or change order of tasks, speed or rate of work, methods of work, etc.), organizational participation (consulted about objectives, involved in improving work organization or work processes and ability to influence decisions important for your work), and training (on-the-job training, training paid for or provided by employer); (6) Prospects, a dimension evaluated through the employment status (self-employed or employee, and type of contract between employees), career prospects (good prospects for career advancement), job security (possibility of losing the job in the next six months), and downsizing (increase or decrease of the workforce in last three years); (7) Earnings, quantified with a single item referring to net monthly earnings from a person's main paid job.

With respect to the reliability of these measures, the meta-analysis carried out by [1] reveals that the JQI has been assessed as comprehensive in coverage and transparent in method.

Considering the entire sample, Table 2 shows some descriptive statistics and bivariate correlations of the key variables in this research. As we can see, the surveyed people indicate a well-being level of 68.09 out of 100. From another angle, the best scores of job quality dimensions are the working time quality index (84.51), the physical environment index (83.7) and the social environment index (76.91). The table also shows that most job quality dimensions correlate with each other and with the main variable of this study. Therefore, well-being presents a positive and meaningful correlation with the indices of work intensity, social environment and prospects, as well as a negative correlation with the skills and discretion index.

Table 2. Descriptive statistics and intercorrelations for the study variables.

\begin{tabular}{lccccccccc}
\hline \multicolumn{1}{c}{ Variable } & Mean & SD & $\mathbf{1}$ & $\mathbf{2}$ & $\mathbf{3}$ & $\mathbf{4}$ & $\mathbf{5}$ & $\mathbf{6}$ & $\mathbf{7}$ \\
\hline 1. Physical environment & 83.78 & 14.38 & 1 & & & & & \\
2. Work intensity & 57.89 & 25.50 & $0.361^{* * *}$ & 1 & & & & \\
3. Working time quality & 84.51 & 22.42 & $0.118^{* * *}$ & $0.112^{* * *}$ & 1 & & & \\
4. Social environment & 76.91 & 24.21 & $0.149^{* * *}$ & $0.132^{* * *}$ & $0.065^{* * *}$ & 1 & & \\
5. Skills and discretion & 67.38 & 26.24 & $0.078^{* * *}$ & $0.028^{* * *}$ & $-0.021^{* *}$ & $0.050^{* * *}$ & 1 & \\
6. Prospects & 62.54 & 20.26 & $0.122^{* * *}$ & -0.005 & $0.045^{* * *}$ & $0.145^{* * *}$ & $0.271^{* * *}$ & 1 \\
7. Earnings & 1566.5 & 957.4 & $0.097^{* * *}$ & $0.081^{* * *}$ & $0.124^{* * *}$ & 0.009 & $0.344^{* * *}$ & $0.300^{* * *}$ & 1 \\
8. WHO-5 & 68.09 & 20.31 & $0.018^{* * *}$ & $0.033^{* *}$ & -0.011 & $0.088^{* * *}$ & $-0.019^{*}$ & $0.058^{* * *}$ & 0.014 \\
\hline
\end{tabular}

Source: Authors' own data. Note: All indices are normalized in a range of 0 to 100 points (except earnings, that are expressed in euros). ${ }^{*} p<0.05 ;{ }^{* *} p<0.01 ;{ }^{* * *} p<0.001$.

\subsection{Data Analysis}

According to the empirical plan of this research, in the first stage, descriptive statistics are presented, grouped by type of country: Piigs or Farmers. Afterward, in the second stage, two linear regression models (Piigs and Farmers) will be estimated using the forward step method of entering variables in the equation. This approach refines better the final model, correcting potential issues of correlation among variables. The default criteria of $p<0.05$ is used to this aim. The complete well-being model is as follows:

$$
\text { Well-being }=\beta_{0}+\beta_{1} \mathrm{Pe}+\beta_{2} \mathrm{Wi}+\beta_{3} \mathrm{Wtq}+\beta_{4} \mathrm{Se}+\beta_{5} \mathrm{Sd}+\beta_{6} \mathrm{Pr}+\beta_{7} \text { Ear }+\varepsilon
$$

Note: Pe (Physical environment), Wi (Work intensity), Wtq (Working time quality), Se (Social environment), Sd (Skills and discretion), Pr (Prospects) and Ear (Earnings).

\section{Results}

\subsection{An Overview of Job Quality Index}

The dimensions of job quality for the period of 2010-2015 are presented in Table 3. An overall view notes that in 2015, Piigs workers held more precarious working conditions in all the indices analyzed, with only one exception: the social environment index. Moreover, it is observed that the 
labor market has degenerated in these years in the Piigs countries, something that has not generally happened in the Farmers countries. We must remember that the indices are normalized in a range of 0 to 100 points (except earnings, that are expressed in euros), so that job quality enhances as the score approaches 100. A similar trend is observed with regard to the level of well-being. The Farmers workers state an overall well-being score of 69.1 points, 2.3 points more than Piigs workers. These scores involve an improvement of well-being in the case of Farmers during the last quinquennium (from 68.0 to 69.1), and a recoil between the Piigs (from 67.3 to 66.8).

Table 3. Job quality dimensions and well-being (2010-2015).

\begin{tabular}{ccccccccc}
\hline & $\mathbf{( 1 )}$ & $\mathbf{( 2 )}$ & $\mathbf{( 3 )}$ & $\mathbf{( 4 )}$ & $\mathbf{( 5 )}$ & $\mathbf{( 6 )}$ & $\mathbf{( 7 )}$ & WHO-5 \\
\hline Piigs (2015) & 82.6 & 57.3 & 80.8 & 81.5 & 60.6 & 55.7 & 1238 & 66.8 \\
\hline Farmers (2015) & 84.5 & 58.2 & 86.6 & 74.6 & 71.2 & 66.4 & 1720 & 69.1 \\
\hline Piigs (2010) & 82.7 & 59.5 & 80.7 & - & 59.3 & - & 1.316 & 67.3 \\
\hline Farmers (2010) & 83.2 & 58.2 & 86.9 & - & 66.4 & - & 1.573 & 68.0 \\
\hline
\end{tabular}

Source: Authors' own data. Note: (1) Physical environment, (2) Work intensity, (3) Working time quality, (4) Social environment, (5) Skills and discretion, (6) Prospects, (7) Earnings.

This first panoramic view seems to justify the thesis that job quality is more precarious in those countries that have been hit harder by the economic crisis. Therefore, each of these indicators is studied in depth to understand the main elements that have degraded the labor market. The entire information is included in Appendix A.

PHYSICAL ENVIRONMENT INDEX. This indicator that measures physical risks at work stands at 84.5 points among the Farmers workers and drops to 82.6 points among the Piigs workers. Of the three risk categories considered in this index (posture-related, ambient and biological and chemical risks), ergonomic risks are the most prevalent for Piigs workers, particularly those who are forced to perform repetitive movements with the hands or arms (64.6\% state that this risk is present in their workplace) or those who involve tiring or painful positions $(49.9 \%)$. These risks are too the most accentuated in the Farmers countries: $59.5 \%$ and $39.5 \%$, respectively.

WORK INTENSITY INDEX. Quantitative demands, pace determinants, interdependency and emotional demands of work are placed in the work intensity index. Table 3 proves that work intensity in Farmers countries (58.2) is better than in Piigs nations (57.3). Piigs workers support more quantitative demands than Farmers workers regarding work at a very high speed (38.6\% vs. $32.2 \%)$ and with tight deadlines (38.8\% vs. $35.9 \%)$. However, workers in the former group suffer less frequent disruptive interruptions ( $33.4 \%$ vs. $40.2 \%$ ), and only $7.9 \%$ believe that they do not have enough time to get the job done, versus $11.7 \%$ of the Farmers workers. Regarding the pace determinants and interdependency, there is a greater interdependence in the Piigs countries relative to the direct control of the supervisors $(39.1 \%$ vs. $30.0 \%)$ and the dependence on automatic speed of a machine or movement of a product ( $21.8 \%$ vs. $14.6 \%)$. In contrast, the work intensity of Farmers countries is more demanding in terms of dependence on numerical production targets or performance targets ( $43.8 \%$ vs. $37.6 \%)$, work done by colleagues (39.8\% vs. $38.8 \%$ ) and direct demands of customers, patients, and pupils. (68.3\% vs. $68.1 \%)$. Finally, emotional demands are more frequent among the Piigs workers. These workers must often hide their own feelings (33.1\%, vs. $31.1 \%$ of Farmers workers) and deal with angry customers $(24.5 \%$ vs. $11.4 \%$ ). In spite of everything, Farmers workers affirm being in situations that are emotionally disturbing more frequently than Piigs workers do (29.5\% to $29.1 \%)$.

WORKING TIME QUALITY INDEX. An overview of this index reveals that the working time of Farmers workers (86.6 points) presents more quality than that of the Piigs workers (80.8\%), a gap that has remained unchanged in last five years (see Table 3). There are three main pillars of this index. In the first place, regarding the duration of the working day, it is observed that, on average, Piigs workers work $36.9 \mathrm{~h}$ per week, compared to the average $35.3 \mathrm{~h}$ of Farmers workers. In addition, $18.6 \%$ of the Piigs workers work more than 48 hours per week on a regular basis, 4.0 percentage points 
more than Farmers workers. In spite of this, the working day of Piigs workers is less lengthy, since $26.7 \%$ claim to work more than $10 \mathrm{~h}$ a day at least once a month, compared to $37.8 \%$ of the Farmers who report the same. Atypical working time is another factor that determines job quality. Therefore, Piigs workers' conditions are more precarious because they work most frequently on Saturdays (55.3\% do so at least once a month, compared to $46.6 \%$ of Farmers workers) and work more often in shifts $(20.0 \%$ vs. $17.1 \%)$. However, the Farmers workers work somewhat more at night $(19.4 \%$ vs. $19.2 \%)$ and on Sundays (32.5\% vs. $30.7 \%$ ). One more point that influences the work-life balance is flexibility and control over working time arrangements. For a large majority of Piigs workers, work schedules are set by the organization, with no possibility of change $(60.5 \%$, almost 14 points more than Farmers workers, at $46.7 \%$ ). In addition, only $29.6 \%$ find it very easy to take one or two free hours during the working day to address personal issues, a ratio that rises to $32.1 \%$ in the Farmers countries. Farmers workers are more impacted by having to work during free time to meet labor demands: $47.8 \%$ compared to $43.0 \%$ of Piigs workers.

SOCIAL ENVIRONMENT INDEX. This index, which analyzes the social environment of the employee, is the only one in which the Piigs countries ( 81.5 points) score better than the Farmers countries (74.6 points). There are three essential dimensions of this index. On the one hand, management quality, which shows that workers have a good opinion of their supervisors, since $90.1 \%$ of Piigs workers and $89.9 \%$ of Farmers workers believe that their bosses respect them as people and three out of four consider their supervisors to be successful in getting people to work together (69.8\% of Farmers workers). In addition, approximately seven out of ten workers admit that their supervisors provide feedback, are helpful in getting the job done and support and reinforce personal growth. However, Farmers workers state that their bosses praise and recognize work well done to a greater extent: $72.5 \%$ versus $68.9 \%$. This apparently better work environment is reinforced by greater social support: $76.0 \%$ of the Piigs workers assert they count on the support of their coworkers (74.9 in Farmers countries), and 66.7\% report support from their superiors (6.7 points more than reported by Farmers workers). Finally, the social environment is more precarious for Farmers workers in terms of adverse social behavior. The ratio of employees who are subjected to some type of abuse in their workplace reaches unacceptable levels in many cases: verbal abuse (14.2\% of Farmers workers vs. $6.7 \%$ of Piigs workers), humiliating behavior ( $7.4 \%$ and $4.3 \%$, respectively), unwanted sexual attention $(2.4 \%$ and $1.3 \%$, respectively) and being threatened (5.9\% and $3.1 \%$, respectively).

SKILL AND DISCRETION INDEX. The result of this indicator is higher in Farmers countries than in Piigs countries (71.2\% vs. 60.6\%), a fact that is better understood by exploring the four elements on which this index is built. First, the cognitive dimension of work highlights that $81.9 \%$ of Piigs workers must solve unexpected problems by themselves (87.6\% in Farmers countries), which surely justifies why $59.0 \%$ note that they can apply their own ideas in work (3.2 points more in the Farmers group). From the pigs workers, $63.7 \%$ must learn new things at work (78.9\% in the Farmers group) or develop complex tasks (50.5\% and $66.9 \%$, respectively). Second, regarding decision latitude, the Farmers workers have more leeway in the choice of task order $(73.9 \%$ vs. $65.4 \%)$, the rate of work $(72.9 \%$ vs. $69.7 \%$ ) and the method of work (74.6\% vs. $65.9 \%)$. However, the Piigs workers note more freedom in regards to the choice of work colleagues (38.8\% vs. $27.8 \%$ ). Third, organizational participation also determines job quality or precariousness. Participation is shown by the fact that the Piigs workers are involved in the improvement of organization of work or work processes that affect their department or organization (52.9\% vs. $52.5 \%$ of the Farmers workers), in that they have the ability to influence important decisions that affect their jobs $(47.7 \%)$, and they are consulted about the objectives that affect their work before changes are implemented (42.3\%). In these last two cases, the Farmers workers exhibit a higher level of participation: $52.1 \%$ and $49.5 \%$, respectively. Finally, access to training is another issue in which the Piigs workers score lower in comparison to the Farmers workers. Only $31.0 \%$ of the former have received training paid by the company, 15.1 points less than the Farmers workers. This gap is even wider in terms of on-the-job training received in the last year: $21.6 \%$ and $40.4 \%$, respectively. 
PROSPECTS INDEX. The workers' labor expectations are collected through the prospects index. As seen in Table 3, this index presents the poorest level of quality, both in the Farmers countries (66.4 points) and, especially, in the Piigs countries (only 55.7 points). Again, four elements compose this index. First, employment status manifests a large gap between Piigs and Farmers countries. Self-employment among the former is much more pronounced-it is virtually double: $24.5 \%$ compared to $12.6 \%$. The remainder work as employees ( $75.5 \%$ and $87.4 \%$, respectively), either with an indefinite contract $(67.0 \%$ vs. $83.6 \%)$, with a temporary contract that is direct or through a temporary employment agency $(20.9 \%$ vs. $12.7 \%)$ or, even worse, work without a contract and, therefore, without any type of legal security $(12.1 \%$ vs. $3.7 \%$, which is an almost fourfold difference between Piigs and Farmers countries). Second, in relation to career prospects, it should be noted that $34.1 \%$ of Piigs workers believe that their job holds good prospects for career advancement. This ratio is much lower than that found in Farmers countries, since almost four out of 10 workers are optimistic in this regard (39.4\%). The third element of this index focuses on job security. Once again, it can be observed that precariousness widely affects the Piigs workers, since $22.7 \%$ are worried about the possibility of losing their jobs in the next six months, a percentage much higher than that of the Farmers group (19.9\%). Finally, the downsizing dimension highlights that the Piigs workers' companies have experienced workforce reduction in recent years $(27.2 \%)$, an outcome higher than that observed in the Farmers workers' companies $(22.3 \%)$. Conversely, only $12.2 \%$ of Piigs enterprises have increased their workforces compared to $27.1 \%$ of Farmers' companies.

EARNINGS INDEX. According to this index, Piigs workers earn almost 500 euros less net per month than Farmers workers: 1238 euros compared to 1720. This gap has duplicated during the period of 2010-2015 because in this time, the net monthly earnings of the former were reduced (in 2010, Piigs workers earned 1316 euros/month), while those of the latter increased (Farmers workers earned 1573 euros/month five years ago). Surely, these figures result in dissatisfaction among the Piigs workers, $34.8 \%$ of these whom believe that they are not being properly rewarded, which is 5.6 percentage points more than Farmers workers who believe the same.

\subsection{Job Quality and Well-Being}

The preceding analysis shows that in the last five years, there has been a clear reduction in job quality in Piigs countries and that currently, the jobs offered in these countries are more precarious than those offered in Farmers nations. This contingency will have some kind of effect on the health and well-being of European workers. This relationship can be expected because perceived job quality is a measure of how the characteristics of work meet multiple human needs, and consequently, the satisfaction of these needs will result in greater feelings of well-being.

To investigate whether there is a relationship between well-being and each of the seven dimensions of job quality considered together (even after controlling for some basic sociodemographic variables, such as gender, age, and education), Table 4 displays the results of three regression models, one to establish which variables determine the well-being of Piigs workers, another for Farmers workers, and one more that includes the full sample.

Using all the predictor variables together to evaluate which combination is the most efficient in the explanation of well-being, Table 4 shows that the well-being of Piigs workers is determined by a sociodemographic variable and by two of the job quality dimensions. In this way, the well-being of these people increases among workers who perceive a friendly work environment, and it decreases when more skills and discretion are available in the workplace. This occurrence, which also happens among Farmers workers, is worthy of attention, since generally beneficial effects have been attributed to job expansion (greater decision latitude, control, organizational participation, etc.).

In the case of Farmers workers, the influence of job quality dimensions seems wider and clearer, since up to five of the seven indicators show statistically significant results. On the one hand, as with the Piigs model, the well-being of Farmers workers is determined by a good social environment (in a positive sense) and by the skill and discretion index (in a negative sense). On the other hand, another 
three dimensions contribute to the positive mood, vitality and general interest of these workers: having good expectations of a professional career, a less demanding job (with fewer labor demands) and, finally, an improvement in physical working conditions.

Table 4. Well-being regression models (Piigs and Farmers).

\begin{tabular}{ccccccc}
\hline & \multicolumn{2}{c}{ Piigs Model } & \multicolumn{2}{c}{ Farmers Model } & \multicolumn{2}{c}{ Piigs/Farmers Model } \\
\hline & Beta & Sig. & Beta & Sig. & Beta & Sig. \\
\hline Physical environment & 0.028 & 0.323 & 0.062 & 0.013 & 0.027 & 0.132 \\
Work intensity & 0.020 & 0.221 & 0.039 & 0.003 & 0.017 & 0.097 \\
Working time quality & -0.024 & 0.174 & -0.028 & 0.084 & -0.029 & 0.017 \\
Social environment & 0.051 & 0.006 & 0.087 & 0.000 & 0.079 & 0.000 \\
Skills and discretion & -0.027 & 0.030 & -0.035 & 0.009 & -0.039 & 0.000 \\
Prospects & 0.008 & 0.693 & 0.072 & 0.000 & 0.043 & 0.001 \\
Earnings & 0.000 & 0.655 & 0.002 & 0.949 & 0.000 & 0.213 \\
Male & 1.763 & 0.033 & 1.121 & 0.066 & 1.671 & 0.001 \\
Age & 0.032 & 0.358 & -0.021 & 0.395 & 0.008 & 0.696 \\
Piigs & - & - & - & - & -2.971 & 0.000 \\
Constant & 61.297 & 0.000 & 60.983 & 0.000 & 61.509 & 0.000 \\
\hline$R^{2}$ & 0.185 & \multicolumn{7}{c}{0.221} & 0.190 & \\
\hline \multicolumn{7}{c}{ Source: Authors' own data. }
\end{tabular}

Finally, Table 4 presents the results of a third regression model that includes all the workers surveyed, regardless of their origin (Piigs or Farmers). As can be noted, the dummy variable referring to the origin country exerts the greatest influence in the workers' well-being $(\beta=-2.971$, Sig. 0.000$)$. In this way, the well-being of the employees is almost three times lower among those who come from Piigs countries in comparison to the Farmers. In addition, male workers have greater well-being than female workers. Finally, the job quality indices that define the well-being of this common model are the social environment and the expectations of professional career (in a positive sense), and the working time quality and the skill and discretion index (in a negative sense).

\section{Discussion}

The push for sustainable development has been accompanied by a great deal of controversy about what should be developed: the economy, society, or people. The emphasis of early literature on economic development and environmental protection has given way to a broader vision of this concept that focuses on human development and on the values and objectives of people [37]. Adopting a psychological point of view, [3] considers sustainability not only in terms of ecological and social environments but also in terms of the promotion of the well-being of all people.

In this sense, [38] proclaim that new measures of human well-being are needed to replace the classic indicator of gross domestic product (GDP) as the main objective of development at the country level. According to these authors, in order to understand sustainable well-being, new metrics should incorporate ideas from the fields of ecology and psychology. Specifically, exploring the workplace from the viewpoint of positive psychology, [8] declare that sustainable development can only materialize in work environments that promote the health and well-being of workers. This philosophy underlies in the European Employment Strategy, aimed at creating more (quantity) and better (quality) jobs. However, our main claim in this research is that the European project has broken down in recent years as a consequence of the economic and financial crisis that has eroded the well-being levels achieved in Europe before 2008. On this subject, it is necessary to highlight a couple of nuances. In the first place, although macroeconomic indicators have undoubtedly improved in recent years, they occlude the worrying reality that the crisis has not ended. The problem in relation to the term "sustainable development" is that the exit from the crisis has rested on emphasizing the noun "development", while the adjective "sustainable" has been relegated to the background. This increases the risk of 
preemptively closing the wound, since recovering the levels of well-being certainly requires both greater levels of employment and also notable progress in the quality of employment. Second, we must bear in mind that the crisis has not plagued Europe in a homogenous way. The severe adjustment measures applied in peripheral countries have caused a decline in the European convergence process, widening the gap between the north and the south. The question that underlies this work is the following: is the European Union truly sustainable in the long term when there are coexisting markets for precarious jobs that hinder the promotion of the well-being of all European citizens, and not just some of them?

That is precisely the main objective of this work-to point out the need to return to the path of convergence, fair work, and dignified and quality working conditions that recover and guarantee the welfare state in Europe in a homogeneous way. To achieve this goal, we conducted broad-spectrum empirical research, adopting a holistic and systematic approach that allowed us to develop a full overview of job quality problems in the Piigs and Farmers countries, as well as to identify those dimensions that have a greater impact on the promotion of sustainable development, health and well-being of workers. The usefulness of this approach lies in the fact that it allows monitoring and evaluation of the labor market and public policies, especially considering the objectives of human development and the improvement of life quality [39].

The results have broadly confirmed our three research purposes.

First, it has been proven that, in the hardest five years of the crisis, the period of 2010-2015, there was a reduction in perceived job quality, but only in the Piigs countries. In this time, the well-being of Piigs countries regressed slightly, at the same time that it improved among the Farmers workers, which makes sense, given the fact that the starting point of the latter was better. This circumstance surely by the fact that working conditions of the Piigs workers have worsened in a general way in those indices for which homogeneous information is available (the only two indices that cannot be compared are the one that measures the social environment and the one that evaluates the prospects of the employees). Adding to this inequality is the improvement of these rates among the Farmers workers, although they had started from a more advantageous position, which has contributed to widening the north-south gap in Europe. As an example, the monthly net earnings of the Piigs workers were reduced by 78 euros (from 1316 to 1238 euros), while that of the Farmers workers increased 147 euros (from 1573 to 1720 euros). These results are discouraging, as they hinder the opportunity offered by the Sustainable Development Goals process to trigger systemic change in order to build a sustainable future in an increasingly interconnected world [40]. Notably, the present study reveals that the reality of the Piigs countries today is actually less sustainable because it fails to meet at least two of the Sustainable Development Goals: Goal 3, concentrated on ensuring healthy lives and promoting well-being for all people at all ages, and Goal 10, focused on reducing inequality within and among countries.

Second, the current situation of work was compared between the Piigs and Farmers countries, revealing that, in general, the job quality of Piigs workers is clearly worse than that of Farmers workers. The only exception is that Piigs workers indicate sensing a more supportive and friendly social environment, which surely compensates for the greater precariousness registered in the rest of the indices. Without these data, the well-being gap between both groups would be even greater. The "indecencies" are perceived especially in conditions such as the pace of work, dealing with angry customers, unsocial work schedules, inflexibility, poor organizational participation, low access to training, insecurity, limited professional expectations and, finally (and importantly), notably lower earnings. Although some recent studies have partially revealed this fact (e.g., [41], related to happiness; [42], linked to employment security; and, among others, [43], connected to incomes), as far as our knowledge is concerned, there is no published study that has done so with the overall approach used in this work. The picture that these results draw is in line with what was stated in our second research purpose.

Finally, we investigated the relationship between job quality and well-being, given that one of the essential objectives of European policy is the promotion of the health and well-being of workers. 
The relationships between work and well-being are ample and bidirectional, since work impacts well-being, while this is a determining factor in the ability to work and remain employed [20]. Thereby, the literature on public health has revealed the pernicious effects of certain risk factors (e.g., high work demands, poor physical environment, and unsocial working hours) on health and well-being. Likewise, other working conditions (high incomes, employment security, good interpersonal relationships, socioeconomic status, etc.) may act in the opposite direction.

From this perspective, the regression models have confirmed the approaches of our third research purpose, highlighting the great influence of the dummy variable "country" (Piigs or Farmers) on the employees well-being, as well as that the dimensions that define the well-being of the Piigs and the Farmers countries are not identical, alerting us to the elements that carry greater risks. In this way, it is observed that two dimensions of job quality feed a common source for the propagation of well-being in both groups. On the one hand, day-to-day work that takes place in a friendly social environment acts in a positive way. On the other hand, the skills and discretion available to the workers act in a negative sense, which is an effect of great interest, since the academic literature usually recognizes of the positive results of granting more control and attributions to workers (e.g., [44-46]). An explanation for this behavior is surely that not everyone aspires to perform tasks of greater complexity, accept more responsibility, learn new things or be responsible for decisions of greater importance. All of this involves making efforts and taking risks that many people do not want to take on. In short, leaving one's comfort zone in this particular dimension of job quality does not increase the well-being of workers but, in fact, seems to reduce it.

The common trunk branches into two ramifications that are proper and indicate the well-being of the Piigs and the Farmers. For example, male Piigs workers have greater well-being than female Piigs workers, probably because their working conditions are clearly better. In the case of Farmers workers, it is significant that the development of well-being is influenced by up to five of the seven dimensions of perceived job quality. Three other factors are added to the two previously mentioned factors that are shared between the Piigs and Farmers workers: a sustainable and healthy work environment with few physical risks; a low intensity of activity in terms of interdependencies and demands of a quantitative and/or emotional nature; and, finally, expectations that guarantee the future of work and the safety of the workers.

A primary preventative approach aimed at ensuring well-being is the key to sustainability, growth, and success for workers, groups, and organizations [3]. For this to happen, it is imperative that some minimum conditions are manifested. This includes designing and constructing organizational development and individual well-being through the promotion of positive relationships in all areas of life, both personal and professional [4].

This study has significant practical implications, since it exhibits what dimensions should be improved in order to progress towards the articulation of job quality in public policy and private practices in terms of not only overarching principles but also concrete actions. More precisely, this paper has overcome one traditional barrier to policy development: the difficulty of measuring and comparing job quality [47]. In this way, this research has systematically and holistically X-rayed the degradation of job quality in some European countries, as well as its direct effect on the health and well-being of workers. The evidence obtained contributes to the visibility of the problem of sustainable development and decent work so that public authorities become aware of the need to adopt legislative measures to amend this picture.

Likewise, this research can be useful in sensitizing enterprise managers about the problem of job quality. To achieve this aim, it can be argued that the use of responsible and sustainable management models is a duty in itself, although less philanthropic arguments can also be used, due to the strong link between organizational profitability and workers' well-being (e.g., [48]). 


\section{Limitations}

This research displays some limitations, especially of a methodological nature. First, the data source of the EWCS is secondary, so the results must be considered cautiously. A second problem is social desirability. Wages, type of contract, social relations with colleagues and/or supervisors, and other sensitive issues of work environment may be subject to conscious or unconscious biases. Third, although harmonized surveys that have made considerable progress in conceptualizing and measuring job quality only exist in Europe, the reality is that debate about this topic remains open in the academic literature.

Author Contributions: Conceptualization, A.A.-M. and G.G.; Formal analysis, G.G. and F.H.-P.; Investigation, A.A.-M. and J.F.-P.; Methodology, F.H.-P.; Supervision, G.G.; Writing—original draft, A.A.-M.; Writing—review \& editing, A.A.-M., F.H.-P. and J.F.-P.

Funding: This research received no external funding.

Conflicts of Interest: The authors declare no conflict of interest.

\section{Appendix A. An Overview of Job Quality Indices}

Table A1. Physical environment index: proportion of workers.

\begin{tabular}{lcc}
\hline \multicolumn{1}{c}{ Ergonomic Risks } & Piigs & Farmers \\
\hline Tiring or painful positions (a quarter of the time or more) & 49.9 & 39.5 \\
\hline Lifting or moving people (a quarter of the time or more) & 10.1 & 10.2 \\
\hline Carrying or moving heavy loads (a quarter of the time or more) & 33.4 & 30.5 \\
\hline Repetitive hand or arm movements (a quarter of the time or more) & 64.6 & 59.5 \\
\hline \multicolumn{1}{c}{ Ambient and biological risks } & 20.4 & 16.8 \\
\hline $\begin{array}{l}\text { Vibrations from hand tools, machinery (a quarter of the time or more) } \\
\text { Noise so loud that you would have to raise your voice to talk to people (a quarter } \\
\text { of the time or more) }\end{array}$ & 24.5 & 26.9 \\
\hline $\begin{array}{l}\text { High temperatures which make you perspire even when not working (a quarter of } \\
\text { the time or more) }\end{array}$ & 27.7 & 21.8 \\
\hline Low temperatures whether indoors or outdoors (a quarter of the time or more) & 23.0 & 20.1 \\
\hline $\begin{array}{l}\text { Breathing in smoke, fumes (such as welding or exhaust fumes), powder or dust } \\
\text { (such as wood dust or mineral dust) (a quarter of the time or more) }\end{array}$ & 12.8 & 14.0 \\
\hline Breathing in vapors, such as solvents and thinners (a quarter of the time or more) & 11.3 & 8.6 \\
\hline \multicolumn{1}{c}{ Chemical risks } & 18.1 & 15.4 \\
\hline $\begin{array}{l}\text { Handling or being in skin contact with chemical products or substances (a quarter } \\
\text { of the time or more) }\end{array}$ & 8.2 & 7.5 \\
\hline $\begin{array}{l}\text { Tobacco smoke from other people (a quarter of the time or more) } \\
\text { as waste, bodily fluids, laboratory materials, etc. (a quarter of the time or more) }\end{array}$ & 12.2 & 13.8 \\
\hline
\end{tabular}


Table A2. Work intensity index: proportion of workers.

\begin{tabular}{|c|c|c|}
\hline Quantitative Demands & Piigs & Farmers \\
\hline Working at very high speed (three-quarters of the time or more) & 38.6 & 32.2 \\
\hline Working to tight deadlines (three-quarters of the time or more) & 38.8 & 35.9 \\
\hline Enough time to get the job done (never or rarely) & 7.9 & 11.7 \\
\hline Frequent disruptive interruptions & 33.4 & 40.2 \\
\hline \multicolumn{3}{|l|}{ Pace determinants and interdependency } \\
\hline \multicolumn{3}{|l|}{ Interdependency: three or more pace determinants } \\
\hline Work pace dependent on: the work done by colleagues & 38.8 & 39.8 \\
\hline $\begin{array}{l}\text { Work pace dependent on: direct demands from people such as customers, } \\
\text { passengers, pupils, patients, etc. }\end{array}$ & 68.1 & 68.3 \\
\hline Work pace dependent on: numerical production targets or performance targets & 37.6 & 43.8 \\
\hline Work pace dependent on: automatic speed of a machine or movement of a product & 21.8 & 14.6 \\
\hline Work pace dependent on: the direct control of your boss & 39.1 & 30.0 \\
\hline \multicolumn{3}{|l|}{ Emotional demands } \\
\hline Hiding your feelings at work (most of the time or always) & 33.1 & 31.1 \\
\hline $\begin{array}{l}\text { Handling angry clients, customers, patients, pupils, etc. (three-quarters of the time } \\
\text { or more) }\end{array}$ & 24.5 & 11.4 \\
\hline Being in situations that are emotionally disturbing (a quarter of the time or more) & 29.1 & 29.5 \\
\hline
\end{tabular}

Table A3. Working time quality index: proportion of workers.

\begin{tabular}{|c|c|c|}
\hline Duration & Piigs & Farmers \\
\hline Working hours per week & 36.9 & 35.3 \\
\hline Long working hours (48 hours or more a week) & 15.3 & 11.3 \\
\hline No recovery period (less than 11 hours between two working days) & 30.6 & 22.9 \\
\hline Long working days ( 10 hours or more a day) & 26.7 & 37.8 \\
\hline \multicolumn{3}{|l|}{ Atypical working time } \\
\hline Night work & 19.2 & 19.4 \\
\hline Saturday work & 55.3 & 46.6 \\
\hline Sunday work & 30.7 & 32.5 \\
\hline Shift work & 20.0 & 17.1 \\
\hline \multicolumn{3}{|l|}{ Working time arrangements } \\
\hline \multicolumn{3}{|l|}{ Control over working time arrangements } \\
\hline Set by the company & 60.5 & 46.7 \\
\hline Can choose between different schedules & 5.9 & 9.4 \\
\hline Can adapt working hours & 12.2 & 27.5 \\
\hline Entirely determined by self & 21.3 & 16.4 \\
\hline \multicolumn{3}{|l|}{ Change in working time arrangements } \\
\hline No regular change & 74.4 & 66.4 \\
\hline Change the same day & 5.5 & 6.9 \\
\hline Change the day before & 7.5 & 7.5 \\
\hline Change several days in advance & 8.4 & 12.9 \\
\hline Change several weeks in advance & 3.7 & 5.6 \\
\hline Requested to come to work at short notice (at least several times a month) & 12.4 & 12.1 \\
\hline \multicolumn{3}{|l|}{ Flexibility } \\
\hline $\begin{array}{l}\text { Very easy to arrange to take an hour off during working hours to } \\
\text { take care of personal or family matters }\end{array}$ & 29.6 & 32.1 \\
\hline Work in free time to meet work demands (several times a month) & 43.0 & 47.8 \\
\hline
\end{tabular}


Table A4. Social environment index: proportion of workers

\begin{tabular}{|c|c|c|}
\hline Adverse Social Behavior & Piigs & Farmers \\
\hline Exposure to verbal abuse & 6.7 & 14.2 \\
\hline Exposure to unwanted sexual attention & 1.3 & 2.4 \\
\hline Exposure to threats & 3.1 & 5.9 \\
\hline Exposure to humiliating behaviors & 4.3 & 7.4 \\
\hline Exposure to physical violence & 1.0 & 3.2 \\
\hline Exposure to sexual harassment & 0.7 & 1.2 \\
\hline Exposure to bullying / harassment & 3.1 & 7.0 \\
\hline \multicolumn{3}{|l|}{ Social support } \\
\hline Your immediate boss respects you as a person: strongly agree and tend to agree & 90.1 & 89.9 \\
\hline $\begin{array}{l}\text { Your immediate boss gives you praise and recognition when you do a good job: strongly agree and } \\
\text { tend to agree }\end{array}$ & 68.9 & 72.5 \\
\hline Your immediate boss is successful in getting people to work together: strongly agree and tend to agree & 75.6 & 69.8 \\
\hline Your immediate boss is helpful in getting the job done: strongly agree and tend to agree & 72.1 & 62.7 \\
\hline Your immediate boss provides useful feedback in your work: strongly agree and tend to agree & 72.2 & 68.0 \\
\hline Your immediate boss encourages and supports your development: strongly agree and tend to agree & 69.6 & 68.5 \\
\hline Help and support from colleagues (most of the time/always) & 76.0 & 74.9 \\
\hline Help and support from your manager (most of the time/always) & 66.7 & 60.0 \\
\hline
\end{tabular}

Table A5. Skills and discretion index: proportion of workers.

\begin{tabular}{|c|c|c|}
\hline Cognitive Dimension & Piigs & Farmers \\
\hline Solving unforeseen problems & 81.9 & 87.6 \\
\hline Carrying out complex tasks & 50.5 & 66.9 \\
\hline Learning new things & 63.7 & 78.9 \\
\hline Working with computers, smartphones and laptops, etc. (at least a quarter of the time) & 45.8 & 64.4 \\
\hline Ability to apply your own ideas in work ('sometimes', 'most of the time' and 'always') & 59.0 & 55.8 \\
\hline \multicolumn{3}{|l|}{ Decision latitude } \\
\hline Ability to choose or change order of tasks & 73.9 & 65.4 \\
\hline Ability to choose or change speed or rate of work & 72.9 & 69.7 \\
\hline Ability to choose or change methods of work & 74.6 & 65.9 \\
\hline Having a say in choice of work colleagues ('always' or 'most of the time') & 38.8 & 27.8 \\
\hline \multicolumn{3}{|l|}{ Organizational participation } \\
\hline Consulted before objectives are set for own work ('always' or 'most of the time') & 42.3 & 49.5 \\
\hline $\begin{array}{l}\text { Involved in improving the work organization or work processes of own department or } \\
\text { organization ('always' or 'most of the time') }\end{array}$ & 52.9 & 52.5 \\
\hline $\begin{array}{l}\text { Ability to influence decisions that are important for your work ('always' or 'most of } \\
\text { the time') }\end{array}$ & 47.7 & 52.1 \\
\hline \multicolumn{3}{|l|}{ Training } \\
\hline $\begin{array}{l}\text { Training paid for or provided by employer over the past } 12 \text { months (or paid by oneself if } \\
\text { self-employed) (\%) }\end{array}$ & 31.0 & 46.1 \\
\hline On-the-job training over the past 12 months (\%) & 21.6 & 40.4 \\
\hline
\end{tabular}


Table A6. Prospects index: proportion of workers

\begin{tabular}{|c|c|c|}
\hline Employment Status & Piigs & Farmers \\
\hline \multicolumn{3}{|l|}{ Employment status } \\
\hline Self-employed & 24.5 & 12.6 \\
\hline Employee & 75.5 & 87.4 \\
\hline \multicolumn{3}{|l|}{ What kind of employment contract do you have in your main job? } \\
\hline Employee, indefinite contract & 67.0 & 83.6 \\
\hline Employee, fixed-term and temporary employment agency contract & 20.9 & 12.7 \\
\hline Employee, other or no contract & 12.1 & 3.7 \\
\hline \multicolumn{3}{|l|}{ Career prospects } \\
\hline My job offers good prospects for career advancement (strongly agree and tend to agree) & 34.1 & 39.4 \\
\hline \multicolumn{3}{|l|}{ Job security } \\
\hline I might lose my job in the next six months (strongly agree and tend to agree) & 22.7 & 19.9 \\
\hline \multicolumn{3}{|l|}{ Downsizing } \\
\hline \multicolumn{3}{|l|}{$\begin{array}{l}\text { During the last three years (or last year according to seniority in the company), has the number of } \\
\text { employees at your workplace increased, stayed the same or decreased: decrease in employment }\end{array}$} \\
\hline Decreased & 27.2 & 22.3 \\
\hline Increased & 12.2 & 27.1 \\
\hline
\end{tabular}

\section{References}

1. Muñoz de Bustillo, R.; Fernández-Macías, E.; Esteve, F.; Antón, J.I. E pluribus unum? A critical survey of job quality indicators. Socio-Econ. Rev. 2011, 9, 447-475.

2. United Nations. Sustainable Development Goals. 2015. Available online: http://www.un.org/ sustainabledevelopment/sustainable-development-goals / (accessed on 14 January 2019).

3. Di Fabio, A. Constructing and Managing Personal Project, Career Project, Life Project: The Challenge of Sustainability; Faculty of Health Sciences, Hokkaido University: Sapporo, Japan, 2016.

4. Di Fabio, A. Positive Healthy Organizations: Promoting Well-Being, Meaningfulness, and Sustainability in Organizations. Front. Psychol. 2017, 8, 1938. [CrossRef] [PubMed]

5. Theorell, T.; Jood, K.; Järvholm, L.S.; Vingård, E.; Perk, J.; Östergren, P.O.; Hall, C. A systematic review of studies in the contributions of the work environment to ischaemic heart disease development. Eur. J. Public Health 2016, 26, 470-477. [CrossRef] [PubMed]

6. Kivimäki, M.; Jokela, M.; Nyberg, S.T.; Singh-Manoux, A.; Fransson, E.I.; Alfredsson, L.; Bjorner, J.B.; Borritz, M.; Burr, H.; Casini, A.; Clays, E. Long working hours and risk of coronary heart disease and stroke: A systematic review and meta-analysis of published and unpublished data for 603838 individuals. Lancet 2015, 386, 1739-1746. [CrossRef]

7. Bannai, A.; Tamakoshi, A. The association between long working hours and health: A systematic review of epidemiological evidence. Scand. J. Work. Health 2014, 40, 5-18. [CrossRef] [PubMed]

8. Di Fabio, A.; Kenny, M.E. From decent work to decent lives: Positive self and relational management (PS\&RM) in the twenty-first century. Front. Psychol. 2016, 7, 361. [CrossRef] [PubMed]

9. Eurofound. Trends in Job Quality in Europe; Publications Office of the European Union: Luxembourg, 2012.

10. Leschke, J.; Watt, A. Challenges in constructing a multi-dimensional European job quality index. Soc. Indic. Res. 2014, 118, 1-31. [CrossRef]

11. May, B.E.; Lau, R.S.M. A longitudinal study of quality of work life and business performance. South Dak. Bus. Rev. 1999, 58, 3-7.

12. Díaz-Chao, Á.; Ficapal-Cusí, P.; Torrent-Sellens, J. Economic crisis and job quality in Spain: A multi-dimensional and micro-data empirical approach. Soc. Indic. Res. 2016, 125, 613-633. [CrossRef]

13. Clark, A.E. What Makes a Good Job? Job Quality and Job Satisfaction; IZA World of Labor: Bonn, Germany, 2015.

14. Green, F. Demanding Work: The Paradox of Job Quality in the Affluent Economy; Princeton University Press: Princeton, NJ, USA, 2006. 
15. Somarriba, S.; Merino, M.C.; Negro, A. La Calidad del Empleo en España: Un Análisis Desde la Perspectiva de Género; X Jornadas de Economía Laboral (AETT): Madrid, Spain, 2013.

16. González, S.; Guillén, A.M. La calidad del empleo en la Unión Europea. Debate político y construcción de indicadores. Rev. Del Minist. De Trab. E Inmigr. 2009, 81, 71-88.

17. Gust, G. Equality at Work: Philippines; (ILO Subregional Office for South-East Asia and the Pacific Working Paper No. 12); International Labour Organization: Manila, Philippines, 2006.

18. Anker, R.; Chernyshev, I.; Egger, P.; Mehran, F.; Ritter, J. Measuring Decent Work with Statistical Indicators. Int. Labour Rev. 2003, 142, 147-178. [CrossRef]

19. Grimshaw, D.; Fagan, C.; Hebson, G.; Tavora, I. (Eds.) Making Work More Equal: A New Labour Market Segmentation Approach; Oxford University Press: Oxford, UK, 2017.

20. Eurofound. Sixth European Working Conditions Survey-Overview Report; Publications Office of the European Union: Luxembourg, 2017.

21. da Costa, B.R.; Vieira, E.R. Risk factors for work-related musculoskeletal disorders: A systematic review of recent longitudinal studies. Am. J. Ind. Med. 2010, 53, 285-323. [CrossRef] [PubMed]

22. Warr, P. Work, Happiness, and Unhappiness; Routledge: New York, NY, USA, 2007.

23. Karasek, R.A. Job demands, job decision latitude, and mental strain: Implications for job redesign. Adm. Sci. Q. 1979, 24, 285-308. [CrossRef]

24. Karasek, R.; Theorell, T. Healthy Work: Stress, Productivity, and the Reconstruction of Working Life; Basic Books: New York, NY, USA, 1992.

25. Trinkoff, A.M.; Le, R.; Geiger-Brown, J.; Lipscomb, J.; Lang, G. Longitudinal relationship of work hours, mandatory overtime, and on-call to musculoskeletal problems in nurses. Am. J. Ind. Med. 2006, 49, 964-971. [CrossRef] [PubMed]

26. Luchman, J.N.; González-Morales, M.G. Demands, control, and support: A meta-analytic review of work characteristics interrelationships. J. Occup. Health Psychol. 2013, 18, 37. [CrossRef] [PubMed]

27. Van den Brande, W.; Baillien, E.; De Witte, H.; Vander Elst, T.; Godderis, L. The role of work stressors, coping strategies and coping resources in the process of workplace bullying: A systematic review and development of a comprehensive model. Aggress. Violent Behav. 2016, 29, 61-71. [CrossRef]

28. Nielsen, M.B.; Einarsen, S. Outcomes of exposure to workplace bullying: A meta-analytic review. Work Stress 2012, 26, 309-332. [CrossRef]

29. Samnani, A.K.; Singh, P. 20 years of workplace bullying research: A review of the antecedents and consequences of bullying in the workplace. Aggress. Violent Behav. 2012, 17, 581-589. [CrossRef]

30. De Witte, H.; Pienaar, J.; De Cuyper, N. Review of 30 years of longitudinal studies on the association between job insecurity and health and well-being: Is there causal evidence? Aust. Psychol. 2016, 51, 18-31. [CrossRef]

31. de Jong, T.; Wiezer, N.; de Weerd, M.; Nielsen, K.; Mattila-Holappa, P.; Mockałło, Z. The impact of restructuring on employee well-being: A systematic review of longitudinal studies. Work Stress 2016, 30, 91-114. [CrossRef]

32. Ng, W.; Diener, E. Affluence and Subjective Well-Being: Does Income Inequality Moderate their Associations? Appl. Res. Qual. Life 2018, 1-16. [CrossRef]

33. Van Aerden, K.; Moors, G.; Levecque, K.; Vanroelen, C. The relationship between employment quality and work-related well-being in the European Labor Force. J. Vocat. Behav. 2015, 86, 66-76. [CrossRef]

34. Piasna, A. 'Bad Jobs' Recovery? European Job Quality Index 2005-2015; ETUI aisbl: Brussels, Belgium, 2018.

35. Topp, C.W.; Østergaard, S.D.; Søndergaard, S.; Bech, P. The WHO-5 Well-Being Index: A systematic review of the literature. Psychother. Psychosom. 2015, 84, 167-176. [CrossRef] [PubMed]

36. Krieger, T.; Zimmermann, J.; Huffziger, S.; Ubl, B.; Diener, C.; Kuehner, C.; Holtforth, M.G. Measuring depression with a well-being index: Further evidence for the validity of the WHO Well-Being Index (WHO-5) as a measure of the severity of depression. J. Affect. Disord. 2014, 156, 240-244. [CrossRef]

37. Kates, R.W.; Parris, T.M.; Leiserowitz, A.A. What is sustainable development? Goals, indicators, values, and practice. Environ. Sci. Policy Sustain. Dev. 2005, 47, 8-21.

38. Costanza, R.; Fioramonti, L.; Kubiszewski, I. The UN Sustainable Development Goals and the dynamics of well-being. Front. Ecol. Environ. 2016, 14, 59. [CrossRef]

39. Pineda, J.A.; Acosta, C.E. Job Quality: Theoretical Exploration and Index Estimation. Ens. Sobre Política Económica 2011, 29, 60-105. [CrossRef] 
40. Costanza, R.; Daly, L.; Fioramonti, L.; Giovannini, E.; Kubiszewski, I.; Mortensen, L.F.; Pickett, K.E.; Ragnarsdottir, K.V.; De Vogli, R.; Wilkinson, R. Modelling and measuring sustainable wellbeing in connection with the UN Sustainable Development Goals. Ecol. Econ. 2016, 130, 350-355. [CrossRef]

41. Bonasia, M.; Napolitano, O.; Spagnolo, N. Happy PIIGS? J. Happiness Stud. 2018, 19, 1763-1782. [CrossRef]

42. Lewchuk, W. Precarious jobs: Where are they, and how do they affect well-being? Econ. Labour Relat. Rev. 2017, 28, 402-419. [CrossRef]

43. Garofalo, A.; Castellano, R.; Punzo, G.; Musella, G. Skills and labour incomes: How unequal is Italy as part of the Southern European countries? Qual. Quant. 2017, 1-30. [CrossRef]

44. Kossek, E.E.; Lautsch, B.A.; Eaton, S.C. Telecommuting, control, and boundary management: Correlates of policy use and practice, job control, and work-family effectiveness. J. Vocat. Behav. 2006, 68, 347-367. [CrossRef]

45. Eisenberger, R.; Cummings, J.; Armeli, S.; Lynch, P. Perceived organizational support, discretionary treatment, and job satisfaction. J. Appl. Psychol. 1997, 82, 812-820. [CrossRef] [PubMed]

46. Wharton, A.S. The affective consequences of service work: Managing emotions on the job. Work Occup. 1993, 20, 205-232. [CrossRef]

47. Charlesworth, S.; Welsh, J.; Strazdins, L.; Baird, M.; Campbell, I. Measuring poor job quality amongst employees: The VicWAL job quality index. Labour Ind. A J. Soc. Econ. Relat. Work 2014, 24, 103-123. [CrossRef]

48. Arnoux-Nicolas, C.; Sovet, L.; Lhotellier, L.; Di Fabio, A.; Bernaud, J.-L. From meaning of working to meaningful lives: The challenges of expanding decent work. Front. Psychol. 2016, 7, 1119.

(C) 2019 by the authors. Licensee MDPI, Basel, Switzerland. This article is an open access article distributed under the terms and conditions of the Creative Commons Attribution (CC BY) license (http:// creativecommons.org/licenses/by/4.0/). 